\title{
LEITURA DE MÍDIAS MÓVEIS COMO ESTRATÉGIA COMPLEMENTAR DE PROJETO
}

\section{READING MOBILE MEDIA AS COMPLEMENTARY STRATEGY FOR $D E S I G N$}

\author{
Gustavo Henrique Campos de Faria ${ }^{1}$ \\ Universidade Federal de Minas Gerais, Belo Horizonte, MG, Brasil, guscamfar@live.com
}

Carlos Eduardo Verzola Vaz ${ }^{2}$

Universidade Federal de Santa Catarina, Florianópolis, SC, Brasil, cevvoo@gmail.com

Sara Dotta Correa ${ }^{3}$

Universidade Federal de Santa Catarina, Florianópolis, SC, Brasil, dottadottynha@gmail.com

\author{
Larissa Pereira de Souza ${ }^{4}$ \\ Universidade Federal de Santa Catarina, Florianópolis, SC, Brasil, laripereiradesouza@gmail.com
}

\begin{abstract}
Resumo
O uso de dispositivos móveis e a emergência da cultura de aplicativos proporcionam novas formas de interação entre sujeito e espaço, promovendo conexão, aprendizado e inovação considerados positivos para a vivência nas cidades. Com isso, a presente pesquisa buscou investigar diversas classes de aplicativos móveis, por intermédio de uma oficina pedagógica com estudantes de Arquitetura e Urbanismo, realizando análises e leituras de objetos midiáticos, com a aplicação do método close reading com lente analítica das poéticas das novas mídias. A ideia principal das poéticas é tornar presente para a consciência humana novas camadas de significação e existência, desvendando e revelando mundos a partir da produção de significados e realidades da cidade permeada por mídias móveis. Os dados do experimento foram coletados por meio de questionários, observação participante e grupo focal, os quais foram tratados pela análise de conteúdo da construção do discurso do sujeito coletivo, triangulados juntamente com a literatura existente (remediação, hipermediação e imediação, narrativa, interatividade e agência). Frente ao experimento pedagógico, foi possível compreender como os estudantes consideram e avaliam as possibilidades de pensar criticamente sobre o espaço mediado por mídias móveis. Além disso, os insights obtidos pelas análises podem se tornar informações complementares no diagnóstico arquitetônico, o que pode direcionar a novas possibilidades de solução de projeto. Observou-se também, que as possíveis intervenções podem se materializar em diversas escalas, constituindo-se de intervenções físicas até intervenções legais no âmbito da cidade.
\end{abstract}

Palavras-chave: Aplicativo. Poéticas das novas mídias. Projeto arquitetônico. Projeto urbano.

\begin{abstract}
The use of mobile devices and the emergence of application culture provide new forms of people-space interaction, promoting connection, learning, and innovation positively for city life. With this, the present research sought to investigate several mobile applications classes through a pedagogical workshop with Architecture and Urban Design students, performing analyzes and readings of media objects by applying the close reading method with the poetics of new media as an analytical lens. The main idea of poetics is to present to human consciousness new layers of meaning and existence, unraveling and revealing worlds from the production of meanings and realities of the city permeated by mobile media. The data were collected through questionnaires, participant observation, and focus groups, treated by content analysis of the collective subject's speech construction and triangulated a long with the existing literature (remediation, hyper mediation, immediacy, narrative, interactivity, and agency). Faced with the pedagogical experiment, it was possible to comprehend how students consider and evaluate critical thinking possibilities about the space mediated by mobile media. The insights obtained from the analysis can also become complementary information in the architectural diagnosis, leading to new options in design solutions. It was also observed that the possible interventions could be materialized in several scales, ranging from physical to legal interventions within the city.
\end{abstract}

Keywords: App. Poetics of new media. Architectural design. Urban design.

How to cite this article:

FARIA, Gustavo Henrique Campos de; VAZ, Carlos Eduardo Verzola; CORREA, Sara Dotta; SOUZA, Larissa Pereira de. Leitura de mídias móveis como estratégia complementar de projeto. PARC Pesquisa em Arquitetura e Construção, Campinas, SP, v. 11, p. e020023, 2020. DOI: http://dx.doi.org/10.20396/parc.v11i0.8658208 


\section{Introdução}

A presença de dispositivos móveis na sociedade oferece aos usuários uma variabilidade de comunicação e ação no cotidiano das cidades. A popularização dessas tecnologias decorreu da evolução da computação móvel, principalmente pela disseminação de internet sem fio, pelo avanço dos sensores e pela capacidade avançada em executar um sistema operacional (Windows Phone, iOS e Android) (JIN, 2016; LEMOS, 2018; THEOHARIDOU; MYLONAS; GRITZALIS, 2012).

Essas tecnologias, portanto, propiciam a difusão das novas mídias, que podem ser entendidas como objetos culturais que necessitam de um dispositivo tecnológico e computacional para seu funcionamento (MANOVICH, 2001, 2005). McQuire (2010) defende que esses objetos podem contribuir para a construção de novas percepções e consciência de ação social, isto é, a presença de mídias móveis no cotidiano da população redefine as formas de interação entre usuários e espaços.

Nesse contexto, Manovich (2006) explica que essa problemática deve ser explorada do ponto de vista da arquitetura, pois, ao analisar as novas mídias e os espaços urbanos, observa-se uma sobreposição de camadas entre o físico e o virtual, tornando-o híbrido. Assim, faz-se importante destacar que o projeto arquitetônico e urbanístico pode ser visto para além da perspectiva histórica, da construção de linhas, formas e massas (ROWE, 1991), em que a revolução da computação na área da arquitetura pode ser explorada a partir da variabilidade (MANOVICH, 2006). Isto é, a combinação das novas mídias com os conhecimentos de projeto e construção não deve ser restrita a um instrumento de representação, mas incorporada a elementos fluidos, mutáveis, codificados e automatizados em toda a esfera da disciplina. Assim, a informação se transforma em experiência, adaptando-se às novas necessidades da contemporaneidade.

Além disso, a apropriação dos artefatos midiáticos pelas pessoas implica diretamente nos modos de locomover, habitar, trabalhar, divertir e participar da vida urbana. Por essa razão, esses objetos provocam um modelo recém adquirido de se relacionar, não somente com os sentidos humanos, mas provocando novos envolvimentos entre sujeito e espaço. Nesse sentido, a exploração da relação entre as novas mídias e o projeto de arquitetura e urbanismo se apresenta fundamentada na conexão entre pessoas e lugares, considerando que as mídias digitais são instrumentos capazes de proporcionar atores ativos na vida pública, além de promover a conexão, aprendizado e inovação para a vida nas cidades (ABDEL-AZIZ; ABDEL-SALAM; EL-SAYAD, 2016).

Dentro dessa perspectiva, esta pesquisa investigou como as novas mídias podem ser operacionalizadas como ferramentas analíticas de projeto em arquitetura e urbanismo. Para isso, foi realizado um experimento pedagógico com alunos do curso de Arquitetura e Urbanismo da Universidade Federal de Santa Catarina. O experimento foi direcionado para a leitura de diversos aplicativos móveis como produtores de dinâmicas urbanas, a partir do uso das lentes analíticas das poéticas das novas mídias. Foram utilizados os parâmetros de remediação, hipermediação e imediação (BOLTER; GRUSIN, 1999), narrativa (BIZZOCCHI, 2007; RYAN, 2006), interatividade (SALEN; ZIMMERMAN, 2003) e agência (EICHNER, 2013; MURRAY, 1998), os quais possibilitaram insights acerca da interação entre sujeito, mídia e espaço, bem como suas implicações para a disciplina de projeto.

\section{O projeto e a dimensão midiática}

O projeto arquitetônico e urbanístico deve lidar não somente com a forma e o produto resultante do desenho, mas também com a combinação desses elementos e suas 
funções espaciais. Além disso, a disciplina também deve se atentar para a experiência da cidade, em que os aspectos sociais, culturais, econômicos e sustentáveis devem direcionar a concepção de espaços que promovam a qualidade de vida dos cidadãos.

Dentre os princípios de um projeto, verifica-se que algumas diretrizes podem ser adotadas a partir da dimensão midiática móvel. Segundo Lemos (2007), as aplicações móveis podem ser vistas por um sistema gerador de dados, o qual possibilita a compreensão de padrões de comportamento, dinâmicas de uso e ocupação do espaço, tipologias econômicas e relações espaciais-temporais, influenciando na percepção e na experiência do usuário.

Esses padrões resultantes das subjetividades emergentes, frente ao uso de artefatos midiáticos, implicam em transformações de espaços urbanos fundamentadas na individualidade do sujeito, a qual pode ser observada no ambiente a partir da repetibilidade de determinadas condutas. Assim, as mídias móveis se manifestam como instrumentos capazes de desencadear processos de transfigurações espaciais, resultando em percepções e ações a partir das informações das camadas informacionais. Com isso, os artefatos midiáticos proporcionam a personalização da informação, oportunizando a construção coletiva de bancos de dados em tempo real (LEMOS, 2007).

Os vestígios humanos, recorrentes desses sistemas, promovem a análise e a implementação de infraestruturas que envolvem a realidade aumentada, o mapeamento de fluxos, o georreferenciamento de estruturas e a utilização de anotações urbanas, elucidando a camada informacional sob determinados espaços geográficos. Com isso, a adição das mídias móveis para a disciplina de projeto de arquitetura e urbanismo se apresenta como uma possibilidade de representar o mundo e promover interações entre sujeitos e espaços [reais e virtuais], favorecendo uma vida urbana ativa e pública.

Nesse cenário, diversos estudos buscam apresentar reflexões e análises a partir da exploração das mídias móveis, como também da produção de dados decorrentes desses artefatos. De Souza e Silva (2006) apresenta que, em Amsterdam, um aplicativo móvel (jogo locativo) foi desenvolvido para estudantes, de forma a relatar a história da cidade a partir de um mapeamento digital. Nesse caso, o georreferenciamento de narrativas históricas se apresenta como um meio hibridizado, o qual é capaz de ampliar a experiência e o aprendizado dos alunos, a partir da exploração do território.

Já Ribeiro e Lima (2012) apresentam que esses artefatos implicam em transformações nas formas de representação gráfica. Ou seja, a conformação da camada informacional, a partir da construção coletiva (publicação de fotos, textos e áudios), colabora para a estruturação de registros e imagens mentais do espaço habitado. Nessa mesma lógica, Toscano (2017) explora, em seu estudo, que as postagens realizadas em uma mídia móvel e social (Instagram) se apresenta como um instrumento de documentação e análise de dinâmicas socioespaciais urbanas, possibilitando a investigação da sociedade contemporânea.

Outra vertente apresentada pela literatura consiste dos trabalhos desenvolvidos por Lev Manovich (1) e sua equipe. Os pesquisadores exploram o crescente volume de informações e dados gerados pelas mídias móveis para a criação de exposições e intervenções que retratam as cidades do século XXI. Trabalhos como o Visual Earth (2017), On Broadway (2015), Selfiecity (2014), SelfieSaoPaulo (2014), dentre outros, manipulam as informações para além de números e gráficos, representando as dinâmicas econômicas, geográficas, demográficas e perceptivas de determinadas cidades e logradouros públicos. 
À vista disso, pode-se dizer que os artefatos midiáticos se apresentam como instrumentos capazes de produzir, detectar e coletar dados e informações, os quais podem influenciar no projeto de arquitetura e urbanismo a partir de cadeias de açãoreação entre as interfaces que compõem o meio urbano. Além disso, a análise e o monitoramento da camada informacional, possibilita a identificação de padrões comportamentais, tanto no espaço físico quanto no virtual, que refletem na produção espacial e podem direcionar o estabelecimento de critérios e diretrizes de intervenção, decorrentes de dinâmicas geradas por esses objetos.

\section{Leitura de artefatos midiáticos: close reading}

A era digital pode ser compreendida pela facilidade de acesso e compartilhamento de informações, em que artefatos midiáticos e usuários são considerados os principais atores envolvidos no processo de consolidação desse momento histórico (LEMOS, 2018). A estruturação das mídias digitais proporciona novos padrões de interação, em que a combinação de informações digitais sob superfícies físicas modifica as experiências do usuário no espaço urbano. A sociedade está se transformando em um sistema itinerante de geração de informações em tempo real (HOELZL; MARIE, 2016), em que corpos e dados se unificam e todas as ações do sujeito no espaço físico se tornam vestígios e reflexos nas realidades das cidades. Isso porque, "Tornamo-nos verdadeiros habitantes de ambientes eletronicamente mediados, e não mais simples usuários de aparelhos computacionais" (MITCHELL, 2002, p. 78).

Nesse contexto, as poéticas das novas mídias se apresentam como princípios que possibilitam explorar as interações de usuários com mídias, além de seus efeitos no contexto da cidade. O termo poéticas deriva da definição Aristotélica de se fazer ativo, em que, no contexto das novas mídias, pode ser compreendido como os princípios fundamentais pelo qual um objeto é construído, suas funções, efeitos e usos (BORDWELL, 2007). Frosh (2019) argumenta que a ideia principal das poéticas é tornar presente para a consciência humana novas camadas de significação e existência, isto é, produzir sentidos e significados. O autor ainda defende que as mídias são forças poéticas, em que são capazes de desvendar e revelar mundos a partir da produção de significados e realidades diferentes da que o sujeito possui de imediato.

Ao utilizar as poéticas como lentes analíticas para investigação de objetos de mídia, fazse possível sua analogia com o processo de interpretação de um texto. Nesse sentido, Platão e Fiorin $(1999,2006)$, indicam que o significado de um texto decorre da combinação das partes geradoras de sentidos, sendo necessário o conhecimento dos mecanismos que estruturam a significação. Além disso, faz-se necessário a utilização de uma técnica que se aproprie da leitura como um fenômeno complexo, na busca de uma compreensão aprofundada de um objeto a partir de seus padrões significativos.

Com isso, o close reading se apresenta como um instrumento poético (FROSH, 2019). O método surgiu entre os anos 1930 e 1940, como uma técnica da teoria literária, e foi inicialmente elaborado por John Crowe Ransom e os "Novos Críticos", possibilitando uma análise detalhada de um texto, a partir de sua desconstrução (BIZZOCCHI; TANENBAUM, 2011). Com o passar dos anos, a estrutura do close reading foi adaptada para ser utilizada na análise e leitura de mídias digitais, a qual teve aderência por diversos autores da contemporaneidade, como Lavin Maud, Janet Murray, Jim Bizzocchi, Joshua Tanenbaum, Paul Frosh, entre outros. Assim, o close reading utiliza a desconstrução de um artefato cultural digital, explorando, detalhadamente, os significados da experiência para além dos elementos factuais presentes no objeto (BIZZOCCHI; LIN; TANENBAUM, 2011). Isto é, a partir de uma visão fenomenológica e poética, o método busca aprofundar suas análises na essência e na percepção do 
fenômeno, como também da sua manifestação no tempo e espaço (BIZZOCCHI; LIN; TANENBAUM, 2011).

Nesse contexto, a técnica se apoia nas habilidades de observar, documentar, avaliar e comunicar as experiências ao utilizar um artefato de mídia (BIZZOCCHI; LIN; TANENBAUM, 2011). Sua aplicação baseia-se em realizar leituras sucessivas e préestruturadas, de forma a obter a experiência pura do objeto, sendo fundamentada teoricamente (Figura 1). Assim, partir de uma leitura profunda e densa, realizada em diversos ciclos, é evidenciado o fazer ativo de objetos midiáticos a partir da revelação de mundos e novos modos de ação no cotidiano das cidades.

Figura 1 - Método close reading

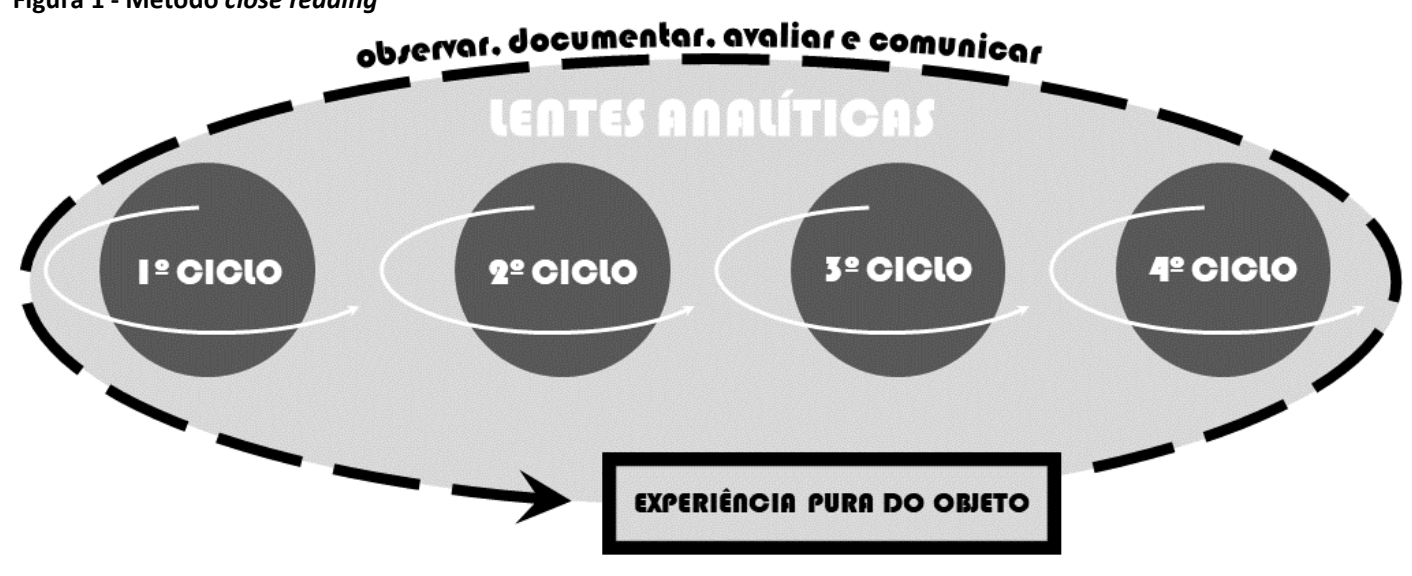

Fonte: os autores.

Esses reflexos na vida urbana se expressam a partir da experiência total da mídia, a qual pode ser alcançada por meio de estratégias que potencializem as relações corporais do sujeito no espaço. Nesse sentido, os questionamentos dos princípios experienciais abordados neste trabalho partiram da exploração das poéticas remediação, imediação, hipermediação, narrativa, interatividade e agência, como explicitadas pelo Quadro 1, buscando compreender os efeitos decorrentes desses princípios na esfera de atuação de arquitetos e urbanistas.

Quadro 1 - Parâmetros de design

\begin{tabular}{|c|c|c|}
\hline POÉTICA & DESCRIÇÃO \\
\hline $\begin{array}{c}\text { REMEDIAÇÃO, } \\
\text { IMEDIAÇÃO E } \\
\text { HIPERMEDIAÇÃO }\end{array}$ & $\begin{array}{r}\text { Remediação baseia-se em duas definições: a primeira, que consiste no fenômeno das novas mídias } \\
\text { adquirirem características de mídias antigas, transformando- se em um novo objeto cultural; e a } \\
\text { segunda, que consiste na oscilação entre imediação e hipermediação (BOLTER; GRUSIN, 1999). A } \\
\text { imediação pode ser compreendida como uma estratégia que permite adentrar na virtualidade do objeto } \\
\text { e a hipermediação é o mecanismo que evidencia o meio por sinais remetidos pela mídia (BOLTER; } \\
\text { GRUSIN, 1999). }\end{array}$ \\
\hline NARRATIVA & $\begin{array}{r}\text { É considerada uma sequência de eventos e permite a criação mental de um cenário e de personagens } \\
\text { ativos, que tornam possível o entendimento de um segmento de uma história (RYAN, 2006). }\end{array}$ \\
\hline INTERATIVIDADE & $\begin{array}{c}\text { Decorre da combinação de fazer escolhas dentro de um sistema e pode ser analisado em quatro níveis, } \\
\text { que são: interatividade cognitiva (envolvimento psicológico, intelectual e emocional do usuário com o } \\
\text { objeto); interatividade funcional (funcionalidade de ação dentro do sistema); interatividade explícita, } \\
\text { (regras pré-estabelecidas pelo sistema); e meta-interatividade (experiências fora da interface do objeto) } \\
\text { (SALEN; ZIMMERMAN, 2003). }\end{array}$ \\
\hline AGÊANCIA & Manifesta-se a partir da experiência do usuário em realizar uma ação, dentro de um sistema, que \\
proporcione um feedback quantificável e prazeroso (EICHNER, 2013; MURRAY, 1998).
\end{tabular}

Fonte: os autores.

Essas poéticas permitem lidar com o fenômeno das novas mídias para além do conteúdo apresentado pelo objeto, permitindo identificar padrões de experiência e como eles se manifestam na realidade. Os conceitos de imediação e hipermediação possibilitam 
investigar tanto a imersão do sujeito na virtualidade, quanto a evidenciação da realidade, ultrapassando os limites do dispositivo tecnológico e atraindo, em diversos níveis, a atenção do usuário.

A narrativa pode ser associada ao prazer de agir interativamente em uma história, como percorrer espaços ou imitar um personagem, oferecendo prazeres para o usuário na forma de narrativa participativa (MURRAY, 1998). Observa-se que essa poética é um importante instrumento potencializador da experiência imaginativa do usuário, e quando combinada às mídias e aos espaços físicos, pode atrair usuários de acordo com a familiaridade de sua estrutura.

A classificação da interatividade em níveis permite investigar desde a exteriorização psicológica e afetiva até a organização de eventos sociais que decorrem fora do sistema midiático (FARIA; VAZ; FADEL, 2019). Por meio das diversas camadas que permeiam a realidade, a interatividade vem se expandindo para além do domínio da computação, influenciando diretamente nas relações entre sujeito, mídia e espaço físico (JIN, 2016).

Por fim, a agência pode ser compreendida pelo desejo que precede a ação (MISKOLCI, 2017) resultando na obtenção de feedbacks significativos para o usuário. Essa poética se expressa de forma situacional, processual, influenciável e intencional a partir das habilidades performáticas do usuário (EICHNER, 2013), implicando diretamente na tomada de decisões do sujeito, seja como usuário midiático ou cidadão.

Ao analisar um artefato de mídia, a experiência do usuário não deve ser resumida à uma única poética, mas sim ao conjunto de fatores que contribuem para fomentar as ações do sujeito e suas relações. Portanto, a análise de objetos culturais, inter-relacionando os parâmetros, permite um estudo minucioso do objeto, buscando pela interpretação das experiências significativas provocadas pela mídia, representando uma fenomenologia construída (BIZZOCCHI; TANENBAUM, 2011) com base na performance do usuário.

\section{Método}

O procedimento adotado estruturou-se na forma de uma oficina pedagógica, visando apresentar uma nova abordagem de análise e interpretação de mídias móveis no campo de arquitetura e urbanismo. O estudo explorou a capacidade investigativa dos alunos, a fim de que esses compreendessem as diversas camadas de realidade que permeiam a sociedade a partir da experimentação de aplicativos móveis em situações reais. O experimento pedagógico ocorreu em quatro momentos, conforme ilustra a Figura 2, direcionando o estudo das mídias pré-selecionadas em três ciclos exaustivos de leitura.

Figura 2 - Estruturação da oficina pedagógica
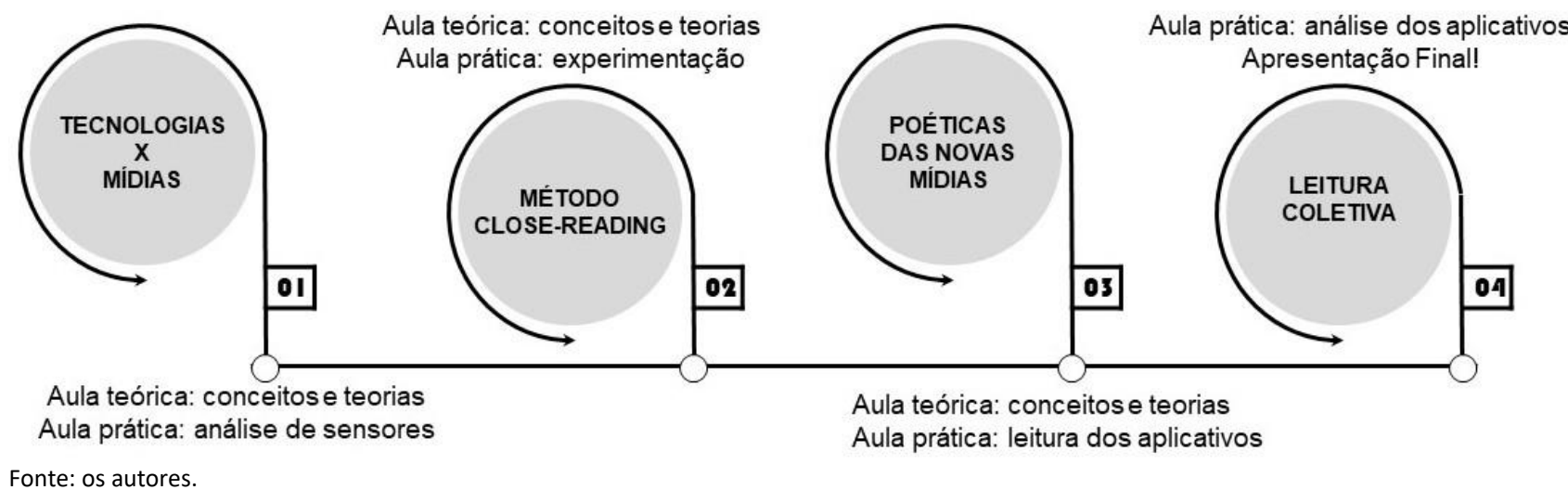

Cada etapa de análise visou identificar a manifestação das poéticas nos objetos e sua relação com as dinâmicas espaciais. As rodas de conversa ao final de cada ciclo de análise 
possibilitaram o compartilhamento das variações de discurso entre alunos, professores e pesquisadores. Além disso, a pesquisa foi direcionada a alunos da graduação, como forma de oportunizar um primeiro contato com as mídias móveis, favorecendo a aplicação dos conceitos e análises apresentadas previamente no decorrer das atividades da disciplina de projeto.

Para o desenvolvimento da oficina, uma lista de aplicativos (Quadro 2) foi previamente selecionada pelos pesquisadores a fim de que cada aluno ficasse responsável pela análise de uma mídia. Os objetos selecionados consistem em artefatos midiáticos que não foram criados para fins arquitetônicos ou urbanísticos, contudo, apresentam importantes implicações no contexto da cidade. A escolha dos aplicativos contemplou aqueles que operam nas plataformas Android e iOS, com versões gratuitas para download e popularmente conhecidos, e optou-se por uma diversidade de classes, como aplicativos de fornecimento de produtos e serviços, jogo geolocativo, mapeamento colaborativo, entre outros. Foram selecionados os objetos com maior número de downloads e que faziam uso do sensor GPS, mesmo que de forma indireta. Além disso, também foi considerada a familiaridade dos estudantes com as mídias, direcionando para um estudo centrado dos objetos.

Quadro 2 - Aplicativos analisados durante oficina

\begin{tabular}{|c|c|c|}
\hline APLICATIVO & DESCRIÇÃO & JUSTIFICATIVA \\
\hline iFood & Delivery de comida e mercado. & $\begin{array}{l}\text { Reportagens relatam as modificações nos fluxos viários após } \\
\text { surgimento do aplicativo. }\end{array}$ \\
\hline Floripa no Ponto & $\begin{array}{c}\text { Informações sobre o transporte coletivo } \\
\text { na cidade de Florianópolis - SC. }\end{array}$ & $\begin{array}{l}\text { Aplicativos de mobilidade urbana podem auxiliar na tomada de } \\
\text { decisões de locomoção. }\end{array}$ \\
\hline Grin & $\begin{array}{l}\text { Aluguel de patinetes elétricas e } \\
\text { bicicletas. }\end{array}$ & $\begin{array}{l}\text { Diversidade nos modos de locomoção vêm alcançando grande } \\
\text { sucesso e modificando dinâmicas locais. }\end{array}$ \\
\hline Strava & $\begin{array}{l}\text { Registro e monitoramento de diversas } \\
\text { atividades e práticas esportivas. }\end{array}$ & $\begin{array}{l}\text { Aplicativos que permitem avaliar desempenho pessoal de práticas } \\
\text { esportivas possibilitam um maior registro de informações sobre } \\
\text { locomoção de usuários pela cidade. }\end{array}$ \\
\hline Ingress & $\begin{array}{l}\text { Jogo geolocativo fundamentado em } \\
\text { realidade aumentada. }\end{array}$ & $\begin{array}{l}\text { Jogos locativos podem gerar novas dinâmicas para os espaços } \\
\text { físicos da cidade. }\end{array}$ \\
\hline Tinder & $\begin{array}{l}\text { Aplicativo para promover } \\
\text { relacionamentos afetivos. }\end{array}$ & $\begin{array}{l}\text { Aplicativos de relacionamentos estão modificando os modelos de } \\
\text { encontro entre desconhecidos. }\end{array}$ \\
\hline WallaMe & $\begin{array}{l}\text { Registro de mensagens secretas em } \\
\text { estruturas urbanas, utilizando-se da } \\
\text { realidade aumentada. }\end{array}$ & $\begin{array}{c}\text { A realidade aumentada possibilita novas formas de interação com } \\
\text { espaços, nesse caso, o aplicativo permite a criação de murais } \\
\text { virtuais sob superfícies físicas reais. }\end{array}$ \\
\hline Spotify & Streaming de música. & $\begin{array}{l}\text { Streamings de música se tornaram um grande sucesso na era da } \\
\text { informação. }\end{array}$ \\
\hline
\end{tabular}

Fonte: os autores.

Os encontros aconteceram durante o período de duas semanas, nos dias 02, 03, 09 e 10 de maio de 2019, como componente didático da disciplina ARQ5324 - Projetos Arquitetônicos para o Futuro, oferecida em caráter eletivo e ministrada pelo Prof. Dr. Carlos Eduardo Verzola Vaz. O conteúdo teórico ministrado na oficina temática conduziu os trabalhos desenvolvidos pelos participantes, proporcionando uma leitura coletiva de artefatos midiáticos, a partir de uma multiplicidade de reflexões em um único ciclo de leituras.

As análises e discussões foram resultados da aplicação do close reading. Considerando que cada aluno foi responsável pela investigação de um aplicativo, foi solicitado que eles registrassem, de forma livre, o processo de leitura dos objetos para uma posterior apresentação. Os estudantes também foram instigados a associarem suas reflexões com o processo de projeto em arquitetura e urbanismo. Ressalta-se que foram realizados grupos de discussões ao final de cada ciclo de leitura dos aplicativos, de forma a obter resultados mais consistentes e fundamentados na coletividade. 
A coleta de dados e informações pertinentes ao estudo foi realizada por meio de observação participante assistemática, dois questionários e aplicação da técnica de grupo focal para as apresentações do trabalho final. O primeiro questionário foi realizado durante o início da oficina e visou obter informações prévias a respeito de um novo conhecimento. Já o segundo avaliou os conhecimentos obtidos e a aplicabilidade de mídias móveis como estratégia de projeto. Essa estrutura do experimento permitiu analisar as dificuldades e facilidades dos alunos com os novos conceitos aprendidos, como também o auxílio nas etapas de execução do close reading. Ressalta-se que todos os participantes autorizaram previamente os registros pela assinatura do TCLE (Termo de Consentimento Livre e Esclarecido) ${ }^{(2)}$.

O suporte de registro do experimento decorreu de anotações, áudio, imagens e questionários impressos. A escolha dessas técnicas baseou-se na estratégia de desencadear um processo de investigação capaz de identificar, compreender, descrever e avaliar as variáveis do fenômeno, estabelecendo relações entre os elementos estudados. Todos os dados coletados foram tratados pelo método de análise de conteúdo, o qual possibilitou a análise, a exploração e o tratamento das informações recolhidas (BARDIN, 2004). A triangulação das evidências coletadas contribuiu para a síntese dos dados qualitativos, relacionando-os com as convergências e divergências da literatura existente.

\section{Resultados e discussão}

Os resultados e discussão desse trabalho serão amparados em três vertentes: Leitura e análises dos aplicativos; Mídia móvel como ferramenta analítica de projeto; e Leitura de mídias móveis e o processo de projeto.

\section{Leitura e análises dos aplicativos}

O primeiro ciclo de leitura buscou compreender os sensores eletromecânicos utilizados pelos aplicativos e suas influências nas dinâmicas urbanas. A análise deu-se pela familiaridade dos estudantes com cada aplicativo, seguida da sua desconstrução em itens operacionais. A associação com a teoria e a funcionalidade de cada sensor também foi considerada para este ciclo de leitura. Após identificação, foi realizada uma discussão geral, em que cada discente apresentou seu aplicativo (Quadro 3).

\begin{tabular}{|c|c|c|}
\hline APLICATIVO & SENSORES ELETROMECÂNICOS & DISCUSSÃO \\
\hline iFood & GPS & $\begin{array}{l}\text { Impactos visíveis no espaço físico; novos modos de trabalhar; } \\
\text { dinâmica de fluxos de veículos (principalmente motos e bicicletas). }\end{array}$ \\
\hline Floripa no Ponto & $\begin{array}{l}\text { GPS (localização do dispositivo como } \\
\text { de veículos de transporte público) }\end{array}$ & $\begin{array}{l}\text { Sincronia de planejamento pessoal; informações em tempo real sobre } \\
\text { a localização dos ônibus. }\end{array}$ \\
\hline Grin & Câmera, GPS & $\begin{array}{l}\text { Privatização do espaço público com inserção de objetos reais pelo } \\
\text { espaço urbano; novos modos de transporte; mobilidade e } \\
\text { infraestrutura. }\end{array}$ \\
\hline Strava & Barômetro, Acelerômetro, GPS & $\begin{array}{l}\text { Senso de comunidade; gamificação do esporte em espaços urbanos; } \\
\text { infraestrutura e segurança urbana. }\end{array}$ \\
\hline Ingress & $\begin{array}{l}\text { GPS, Câmera, Acelerômetro, } \\
\text { Giroscópio }\end{array}$ & $\begin{array}{c}\text { Senso de comunidade; cidade como um espaço de jogo; novas formas } \\
\text { de interagir com o físico possibilitado pela camada virtual. }\end{array}$ \\
\hline Tinder & GPS & $\begin{array}{l}\text { Novos modos de ocupar espaços fechados, promove encontros, } \\
\text { amplia a percepção na busca de encontrar o match pelo espaço físico. }\end{array}$ \\
\hline WallaMe & $\begin{array}{c}\text { Câmera, GPS, Acelerômetro, } \\
\text { Giroscópio, Magnetômetro, Sensor } \\
\text { de movimentos }\end{array}$ & $\begin{array}{l}\text { Déficit de usabilidade no Brasil; propõe a criação de murais virtuais } \\
\text { pela cidade; reduz a poluição visual. }\end{array}$ \\
\hline Spotify & Autofalante, Acelerômetro e GPS & $\begin{array}{l}\text { Pode potencializar as significações do espaço por intermédio de } \\
\text { músicas; propicia informações sobre concertos e shows próximos a } \\
\text { localização do dispositivo. }\end{array}$ \\
\hline
\end{tabular}


O segundo ciclo de leitura buscou identificar a manifestação da poética remediação, em suas duas definições. O Erro! Autoreferência de indicador não válida. apresenta as principais discussões realizadas durante a oficina. Também foi apontada a possibilidade de uma obra de arquitetura ser considerada um objeto cultural e que, a partir de um olhar sensível, seria possível integrar as poéticas de imediação e hipermediação na concepção de novos projetos arquitetônicos e urbanos. Haja vista que as pessoas são os principais usuários e exploradores do espaço construído, percebe-se a oscilação da imersão se manifestando como um mecanismo capaz de ampliar a percepção do espaço e imergir o sujeito na interface, influenciando no modo como as pessoas interagem com o espaço.

\begin{tabular}{|c|c|c|}
\hline APLICATIVO & NÍVEL DE REMEDIAÇÃO & IMEDIAÇÃO E HIPERMEDIAÇÃO \\
\hline iFood & $\begin{array}{l}\text { Próxima do } 3 \text { o nível. Proporciona a } \\
\text { interação do usuário em todas as } \\
\text { etapas de compra de um produto. }\end{array}$ & $\begin{array}{l}\text { Evidencia o meio (hipermediação) provocando a noção espacial das } \\
\text { rotas de entrega do produto. Porém, durante o processo de compra e } \\
\text { o uso de cupons promocionais, percebe-se a manifestação da } \\
\text { imediação. }\end{array}$ \\
\hline Floripa no Ponto & $\begin{array}{l}\text { Próxima do } 3 \text { o nível. Apresenta } \\
\text { informações em tempo real. }\end{array}$ & $\begin{array}{l}\text { O mapa híbrido direciona à hipermediação, levando o usuário a } \\
\text { perceber o contexto externo à mídia, ampliando a compreensão } \\
\text { espaço-temporal de trajetos urbanos. Alarmes potencializam a } \\
\text { imediação, direcionando a atenção para a interface do objeto. }\end{array}$ \\
\hline Grin & $\begin{array}{l}\text { 10 nível. Representa a digitalização } \\
\text { da locação de bicicletas e patinetes. }\end{array}$ & $\begin{array}{l}\text { Amplia a percepção espacial, a partir da busca pelos objetos na } \\
\text { interface híbrida. A imediação se manifesta durante a liberação e a } \\
\text { devolução dos equipamentos reais. Os dados gerados também podem } \\
\text { ser considerados como estratégia de imediação. }\end{array}$ \\
\hline Strava & $\begin{array}{l}\text { 3o nível. Provoca a prática de } \\
\text { esportes, integrando produção de } \\
\text { dados e uso de espaços urbanos. }\end{array}$ & $\begin{array}{l}\text { A hipermediação provoca o uso da infraestrutura real do espaço. Os } \\
\text { dados gerados pelo aplicativo direcionam a imersão do sujeito para a } \\
\text { compreensão dos resultados da prática esportiva. }\end{array}$ \\
\hline Ingress & $\begin{array}{l}\text { Próxima do } 3 \text { o nível. Utiliza da cidade } \\
\text { como espaço de jogo. }\end{array}$ & $\begin{array}{l}\text { Provoca a imersão do usuário baseado em narrativas virtuais } \\
\text { interativas. O georreferenciamento de elementos do jogo provoca a } \\
\text { hipermediação, ampliando a percepção ambiental do usuário. }\end{array}$ \\
\hline Tinder & $\begin{array}{l}\text { 20 nível. Proporciona o encontro } \\
\text { baseado em jogos de carta. }\end{array}$ & $\begin{array}{l}\text { A imediação provoca a imersão do sujeito na interface do objeto a } \\
\text { partir da estratégia de gamificação. A hipermediação decorre do } \\
\text { match, em que direciona o usuário para outras plataformas sociais. }\end{array}$ \\
\hline WallaMe & $\begin{array}{l}\text { 20 nível. Remedia mensagens em } \\
\text { murais, permitindo a interação entre } \\
\text { usuários. }\end{array}$ & $\begin{array}{l}\text { A estratégia de hipermediação leva o usuário a imergir no contexto } \\
\text { físico da cidade, na busca por superfícies passíveis de serem } \\
\text { aumentadas pela tecnologia. A presença de informações somente no } \\
\text { contexto virtual é ocasionada pelo mecanismo de imediação. }\end{array}$ \\
\hline Spotify & $\begin{array}{l}\text { 2o nível. Representa um player de } \\
\text { música, porém permite maiores } \\
\text { interações para o usuário. }\end{array}$ & $\begin{array}{l}\text { As playlists se tornam o principal elemento que possibilita a imersão } \\
\text { do sujeito, em que os algoritmos são desenvolvidos para a } \\
\text { compreensão de padrões de uso, sugerindo conteúdos similares para } \\
\text { consumo. }\end{array}$ \\
\hline
\end{tabular}

Investigou-se a revelação das poéticas narrativa, interatividade e agência no terceiro ciclo de leitura, a partir da desconstrução dos aplicativos em sistemas funcionais, isto é, as principais características manifestadas pelas mídias com influência direta ao espaço urbano. Levando em consideração que nem todas as poéticas se evidenciam em uma mídia, abaixo são apresentadas as principais premissas de cada objeto.

O iFood é desconstruído em três agentes: o usuário, o restaurante e o entregador. Constatou-se que o aplicativo influencia não somente o usuário final, mas todo o percurso do produto, desde a preparação, a entrega e o recebimento pelo consumidor final. Em relação às dimensões narrativas (RYAN, 2006) o aplicativo é favorecido de personagens ativos e providos de emoção (demonstrado pelos feedbacks entre usuários e restaurantes), como também da presença do espaço (restaurante, estrutura viária e residência do usuário). Em relação aos níveis de interatividade, ressalta-se a metainteratividade (SALEN; ZIMMERMAN, 2003), a qual se apresenta como um 
relevante instrumento para o sucesso do aplicativo, a partir de uma cadeia de sociabilização ocasionada pelos cupons promocionais.

O aplicativo Floripa no Ponto é descontruído a partir de três elementos da interface, a parada mais próxima, as linhas de ônibus e o trajeto, que podem ser considerados como como elementos importantes de interação com a interface. A interatividade explícita (SALEN; ZIMMERMAN, 2003) se torna a principal poética do aplicativo, pois não é permitido ao usuário interferir nos trajetos e rotas pré-fixados pelo sistema. Em relação à agência, percebe-se que essa poética se manifesta em situações de compatibilidade de itinerários e rotinas adequados ao usuário. Nessa situação, o aplicativo otimiza as formas de se percorrer a cidade, a partir da sincronização em tempo real dos deslocamentos do transporte público.

De modo a explorar novos modos de locomoção, possibilitados por objetos de mídia, o aplicativo Grin é analisado a partir da perspectiva de fascínio pela tecnologia, ou cinema de atração (GUNNING, 1990). Essa estrutura tecnológica impulsionou o seu uso pela novidade inserida no cotidiano das cidades. Foi verificado muitas das vezes, o custo da viagem de patinete se torna mais cara que outras formas de locomoção. Assim, os motivos que levam a utilização do patinete podem decorrer de diversos fatores, como disponibilidade, comodidade, prazer, sustentabilidade, entre outros. Por meio de relatos dos participantes e pelo uso exaustivo do equipamento, percebeu-se que na cidade de Florianópolis, devido à deficiência de infraestrutura urbana adequada, o uso do patinete provoca instabilidade na segurança pessoal, seja por acidentes ou pela falta de estrutura, em que o próprio patinete se torna um obstáculo nas calçadas.

Já para a aplicação móvel Strava é verificado que os mecanismos de interatividade cognitiva, funcional e explícita (SALEN; ZIMMERMAN, 2003) direcionam o usuário a hipermediação, fazendo-o perceber o espaço físico. A partir dos sensores eletromecânicos do dispositivo, o instrumento se manifesta como produtor e coletor de dados e informações, a partir de registros do processo do atleta, levando-o a um processo de imersão sensorial na prática de esporte. Já a imediação provoca a imersão imaginativa do usuário, em que a narrativa gerada pelo armazenamento e tratamento de dados direciona o usuário para a interpretação e divulgação das informações obtidas, seja no próprio aplicativo ou em outras redes sociais.

Em relação ao jogo Ingress, percebe-se que este apresenta uma relação entre a percepção espacial e a navegação espacial decorrentes da narrativa (BIZZOCCHI; LIN; TANENBAUM, 2011; RYAN, 2006), interatividade (SALEN; ZIMMERMAN, 2003) e agência (EICHNER, 2013). Destaca-se que o prazer de se entregar à uma narrativa proporciona mudanças comportamentais no usuário (BIZZOCCHI; LIN; TANENBAUM, 2011). Assim, verifica-se que a narrativa interativa está progredindo ao longo dos anos e que a indústria midiática, ao incorporar características da narrativa à experiência do usuário, possibilita a construção de novos instrumentos que influenciam diretamente a imersão do jogador à interface (BIZZOCCHI, 2003).

Quanto ao Tinder é verificado que o objeto contém uma narrativa que se faz presente na história da cidade, sendo associada à estrutura das praças e dos espaços públicos que trazem como significante o encontro, a troca (comercial, cultural) e a celebração (GASTAL, 2004), considerando que o aplicativo atua nas conexões virtuais, e rompe com o tempo e espaço das relações. Destacou-se que o aplicativo pode provocar um distanciamento do sujeito com espaços físicos reais, visto que sua natureza se baseia em promover encontros virtuais. Porém, para a materialização do encontro, foi discutido que quase sempre as pessoas recorrem a espaços públicos providos de uma vida urbana ativa e movimentada. 
Já o WallaMe consiste em uma plataforma digital de mensagens publicadas virtualmente, a partir do georreferenciamento em interfaces físicas reais da cidade. A sua funcionalidade se torna um mecanismo que minimiza a poluição visual da paisagem urbana em consequência da natureza de publicações georreferenciadas. Nota-se que o aplicativo oferece novas formas de perceber, experienciar e relatar informações espaciais, exigindo uma interação mútua entre sujeito com a interface virtual e o espaço físico real. O aplicativo também se apresenta como uma ferramenta potencial para comunicar, anunciar e divulgar variadas mensagens - culturais, sociais, históricas, marketing - entre diversificados grupos sociais e de forma sustentável.

Por fim, o Spotify é analisado pela lente analítica da subjetividade do sentido auditivo. Visto que a preferência musical pode variar entre pessoas, foi relatado entre os participantes que, a partir de contextos pessoais, a plataforma oportuniza a significação afetiva (FROSH, 2019) por meio da corporeidade e espacialidade do sujeito em decorrência de determinada música, isto é, a interatividade cognitiva (SALEN; ZIMMERMAN, 2003) se destaca no aplicativo por refletir em gestos, danças e pensamentos íntimos acerca do espaço que se percorre ou contempla. O aplicativo também apresenta a função de notificação de eventos musicais que acontecerão na região em que o dispositivo se encontra, presumindo que essa característica se torna um mecanismo que evidencia a agência pessoal (EICHNER, 2013).

Outrossim, os estudantes foram indagados a relacionarem as leituras dos objetos com possíveis estratégias de intervenção arquitetônica e urbana, os relatos podem ser observados na Figura 3.

Figura 3 - Insights de intervenções arquitetônicas e urbanas

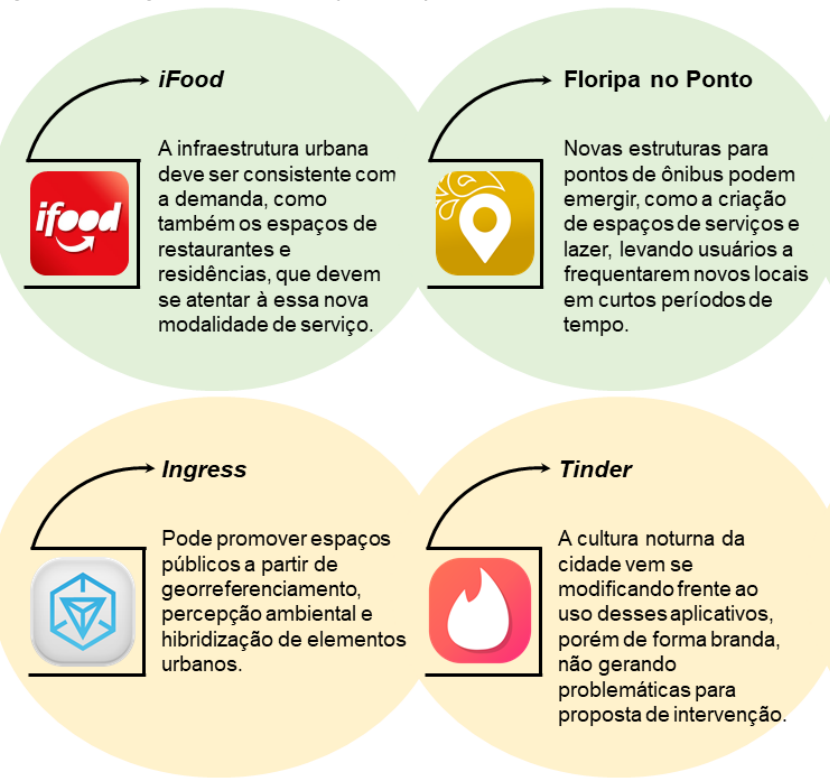

Fonte: os autores.
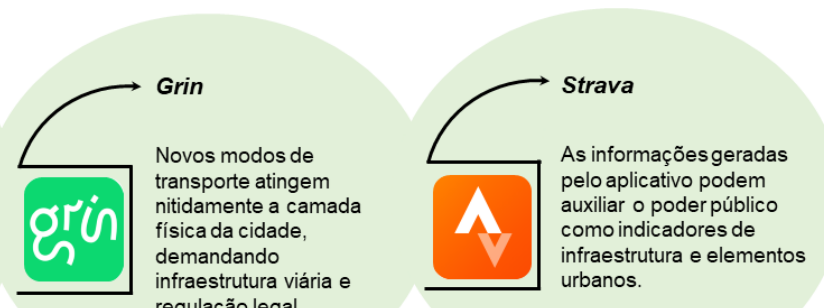
regulação legal.
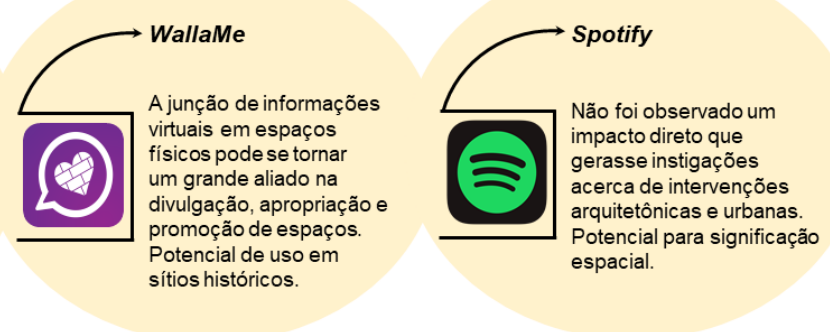

INFLUÊNCIA INDIRETA NO ESPAÇO FISICO

A partir dos insights de intervenção, verifica-se uma influência direta na infraestrutura física dos espaços a partir dos aplicativos que oferecem prestação de serviços e ofertas de produtos. Essa classe, apesar de apresentar pouca disponibilidade de acesso ao banco de dados, manifestam-se de forma visível nos espaços urbanos, como também nos espaços residenciais. Já as aplicações destinadas ao transporte público, novos modos de locomoção e produtores de mapas colaborativos influenciam, não somente o deslocamento do sujeito, mas refletem diretamente nas dinâmicas de fluxos, uso e ocupação de determinados espaços. Assim, pode-se dizer que essas classes se tornam 
capazes de operar como ferramentas de disseminação de interesses públicos, análise e gestão urbana.

Nesse contexto, nota-se que as dinâmicas programadas pela camada midiática se fazem passíveis de serem lidas e analisadas pelo método close reading como também exploradas para a compreensão socioespacial do urbano. Isso porque, fundamentados na sincronia entre dinâmicas socioespaciais e na camada informacional, observa-se a replicação de padrões comportamentais, em que a experiência de uso se manifesta no ser humano para, então, refletir no espaço construído. Dessa forma, a leitura de mídias móveis se transforma em um instrumento que auxilia na compreensão da relação homem-computador, direcionando para a compreensão das dinâmicas espaciais emergentes da difusão desses objetos para a sociedade.

Mídia móvel como ferramenta analítica de projeto

O experimento avaliou o uso de objetos midiáticos como instrumento analítico de projeto a partir de duas categorias de análise: a influência desses objetos na percepção dos usuários e a relação entre processo de projeto e a leitura de mídia móvel. Assim, a partir dos ciclos de leitura, foi observado que o tangenciamento das mídias digitais na produção de dinâmicas socioespaciais reafirma a necessidade da presença de um corpo social, isto é, o indivíduo que pensa, age e vivencia o urbano simultaneamente (VALADARES; TEODORO, 2019).

Em relação a percepção dos estudantes, foi utilizada a escala Likert como estratégia de coleta de dados. Os alunos responderam a dezenove afirmações apontando cinco níveis de posicionamento, que são: discordo totalmente (DT), discordo parcialmente (DP), indiferente (I), concordo parcialmente $(\mathrm{CP})$ e concordo totalmente $(\mathrm{CT})$. As respostas gerais podem ser verificadas na Figura 4.

A partir dos resultados, observa-se que as mídias móveis podem modificar a forma de perceber o espaço urbano, influenciando a estruturação da imagem da cidade por parte das pessoas. A relação sensorial do usuário a partir de aplicativos pode ser considerada uma forma de amplificar a capacidade de pertencimento de comunidade, fortalecer as compreensões espaciais e históricas, além de complementar as interatividades sociais.

Destaca-se, portanto, que esses objetos, ao retirarem o sujeito da posição de espectador, colocando como parte fundamental para a interação sujeito-mídia-espaço, fazem com que o corpo se projete em um objeto metafórico de manuseio e controle, implicando diretamente no modo de estar e pensar, enquanto os componentes estruturantes do espaço, direcionam o sujeito para uma experiência fenomenológica do lugar (NORBERG-SCHULZ, 2008), seja em decorrência da ação, do movimento, da sociabilidade ou da significação. 
FARIA, Gustavo Henrique Campos de et al..

Leitura de mídias móveis como estratégia complementar de projeto

Figura 4 - Percepção dos estudantes mediada por mídias móveis

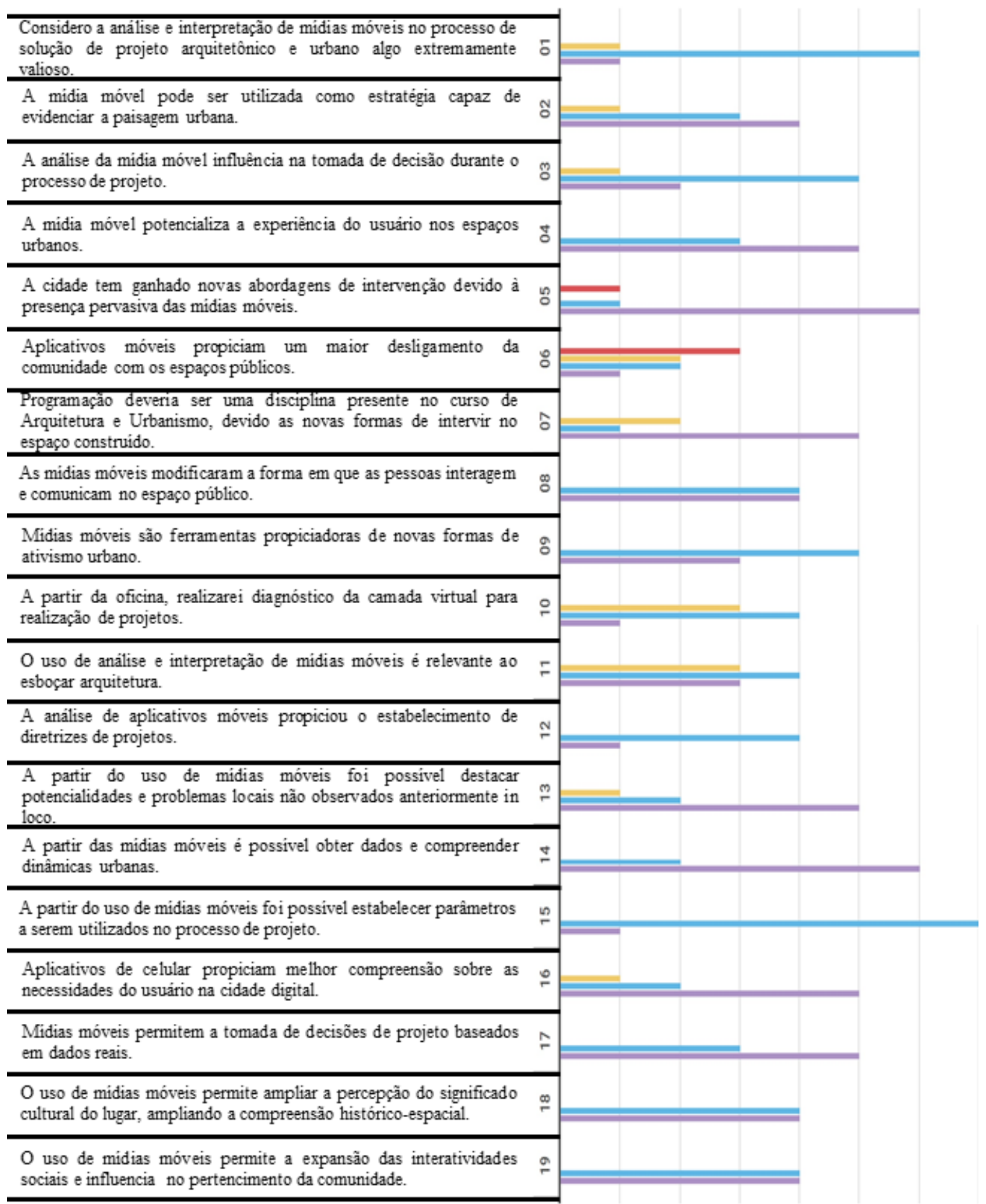

Discordo totalmente

Discordo parcialmente

Indiferente

Concordo pacialmente

Concordo totalmente

Fonte: os autores. 
Essa relação pode ser associada com as leituras de objetos midiáticos realizadas durante o experimento. Tem-se, por exemplo, a manifestação da agência criativa (EICHNER, 2013), decorrente da metainteratividade (SALEN; ZIMMERMAN, 2003) provocada pelo aplicativo Strava. Isso é, a partir da funcionalidade de criar e compartilhar rotas para membros do aplicativo, nota-se a combinação de originalidade e motivação para a prática de esportes, rompendo com a materialidade do traçado urbano, introduzindo o simbolismo nas rotas e trajetos como meio de amplificar a experiência do usuário, conforme ilustra a Figura 5. Dessa forma, compreende-se que essa modalidade de ação possibilita que diversos usuários conheçam novas rotas pela cidade, sugerindo que o mapa mental é ampliado pelo estímulo de se fazer um desenho que antes não era capaz de ser lido por outro.

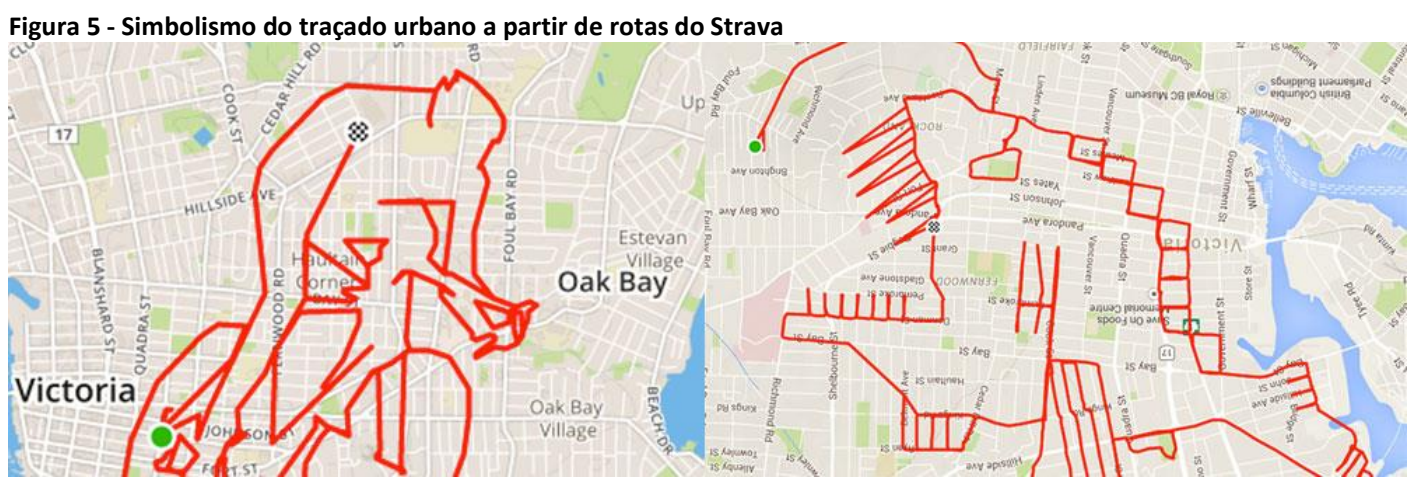

Fonte: Ricupero (2017).

Também foi verificado que se faz possível a coleta de dados e informações importantes na compreensão das dinâmicas da vida urbana. Dessa forma, pode-se dizer que os aplicativos se manifestam como programadores de condutas, em que a partir dos vestígios humanos podem direcionar a implementação de infraestruturas condizentes com as atuais necessidades dos usuários. Isso é, de acordo com cada classe de aplicativo, observa-se uma diferenciação na produção de dinâmicas experienciais, que se exprimem por meio das determinantes de interações e reações. Assim, o input desses objetos pode ser direcionado para a interação corporal do sujeito, toques e gestos, como também a partir de interfaces remotas que utilizam de dados capturados e digitalizados em tempo real (WIETHOFF; HUSSMANN, 2017).

Por exemplo, a classe de aplicativos de serviços híbridos, como o iFood, apresenta-se composta por objetos capazes de modificarem as relações entre consumidor, produtor e fornecedor, refletindo diretamente em novos fluxos para as infraestruturas comerciais, residenciais e viárias da cidade. Já os aplicativos que promovem novos modos de se locomover pela cidade, como o Grin e o Floripa no Ponto, os quais influenciam no deslocamento do sujeito, promovendo novos fluxo para as infraestruturas viárias existentes e implicando na reestruturação de aspectos de regulação urbana.

Nesse contexto, verifica-se que a análise de mídias móveis é constituída pela aquisição de informações e suas correlações para melhor compreensão do contexto em que será desenvolvido um produto, neste caso, o projeto arquitetônico e/ou urbano. E é, a partir da análise, que o meio é observado e explorado, levando à definição de um problema de projeto.

\section{Leitura de mídias móveis e o processo de projeto}

De forma a avaliar a leitura desses objetos como instrumento de analítico de projeto, o experimento também utilizou a escala Likert como técnica de coleta de informações. 
Assim, os estudantes foram indagados quanto aos processos de concepção de projetos, que são estratégias que permitem elucidar a ação do arquiteto e urbanista no processo de projeto. Os resultados obtidos estão apresentados na Figura 6.

A partir dos dados coletados, sugere-se que as leituras desses objetos podem complementar o processo de projeto, visto que ele pode ser compreendido pela tríade análise, síntese e avaliação (JONES, 1963; LAWSON, 2005; ROWE, 1991), em que as mídias acrescentam informações prévias à concepção (análise) ou à avaliação pósocupação de um projeto arquitetônico/urbano, promovendo uma realidade condizente com os elementos físicos e não físicos que compõem a cidade.

Figura 6 - Parâmetros de análise da importância da mídia móvel no processo de projeto

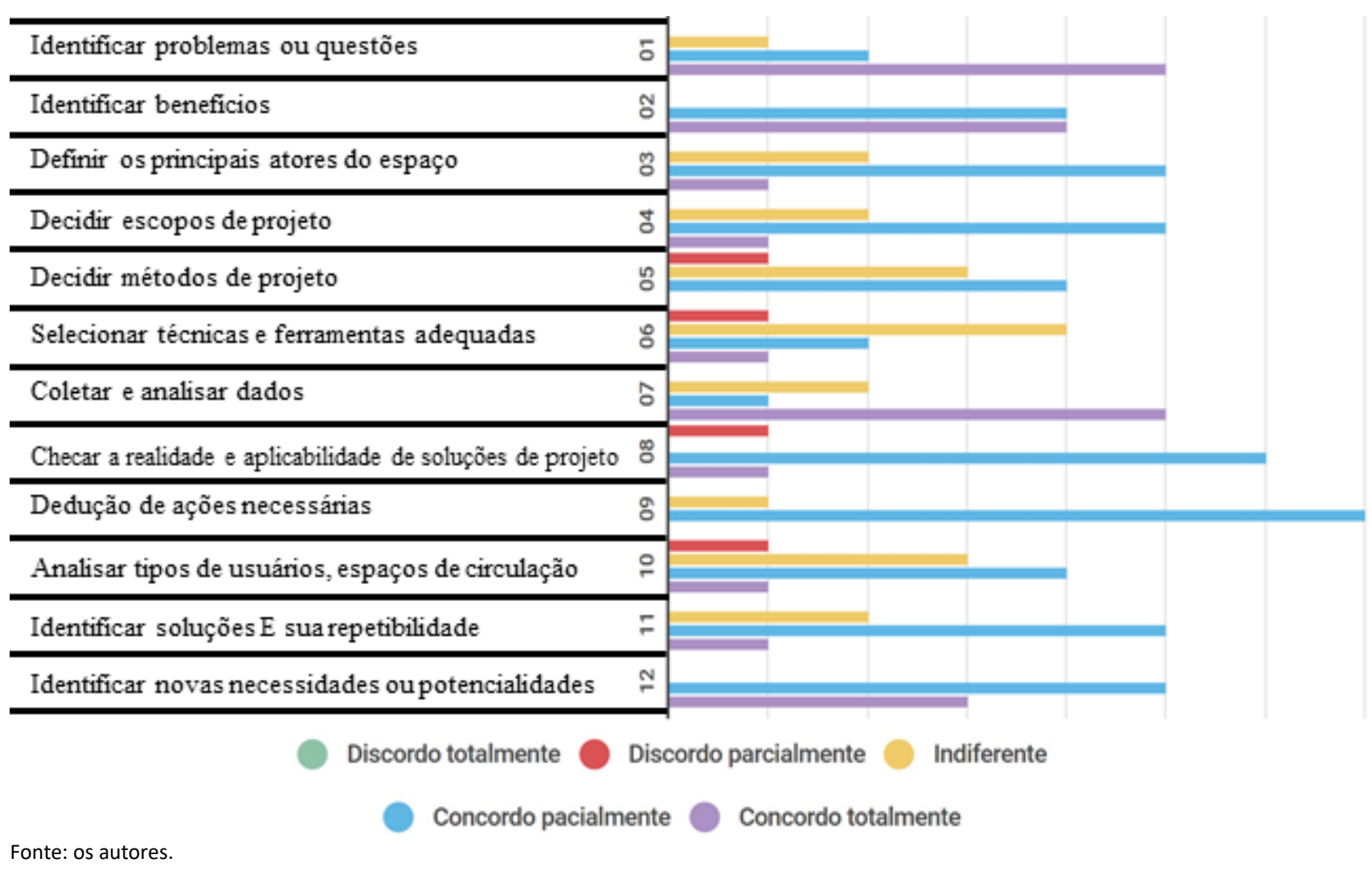

Essa relação também pode ser verificada a partir de trabalhos correlatos, como os de Ribeiro e Lima (2012) e Toscano (2017). Esses autores argumentam que os dados elucidados na conformação espacial permitem a análise dos vestígios da população. Com isso, identifica-se que esses dados podem ser considerados valiosos, permitindo observar os processos de interação do usuário, sem necessariamente exigir custos elevados de pesquisa. As redes digitais ampliam as formas de se ver a cidade e direcionam a exploração da estrutura e composição do urbano, fornecendo alternativas de compreensão dos rastros digitais da população.

Ao projetar, a imaginação visual se desenvolve a partir de métodos e ferramentas de representação, a qual exige a habilidade de manipulação de técnicas específicas (ANDRADE; RUSCHEL; MOREIRA, 2011). Percebe-se que, a partir da análise de leitura de artefatos midiáticos, não se faz possível estabelecer estratégias que definiriam a escolha do ferramental adequado. Essa constatação, proveniente do questionário, pode estar associada a natureza de análise abordada nesse trabalho, a qual possibilita compreender a relação mídia e sujeito e seus reflexos no espaço. Porém, reforça-se os trabalhos desenvolvidos por Lev Manovich, em especial a instalação artística On 
Broadway. Nesse trabalho, o autor utiliza de uma interface digital e visual para a materialização da intervenção arquitetônica, em que todos os dados utilizados pela obra tiveram procedência da camada informacional elucidada pelos cidadãos e turistas. Portanto, observa-se que nesse caso, além da proveniência de dados coletivos, a intervenção se materializa a partir de uma estrutura visual midiática, fazendo-se uso da metáfora da produção constante de dados para a representação das camadas que permeiam a cidade. Dessa forma, foi possível observar que as análises de mídias móveis podem possibilitar a exploração da estrutura e composição da cidade, fornecendo novas formas de compreender os dados gerados pela sociedade.

Por fim, os alunos foram questionados acerca do posterior uso da leitura de mídias móveis como parte do processo de projeto, obtendo-se que $87,5 \%$ gostariam de utilizar, enquanto $12,5 \%$ consideraram a metodologia muito complexa de ser executada. Inferese, consequentemente, que a análise realizada foi considerada importante para os estudantes, porém dificuldades relacionadas ao método são consideradas como um fator para desistência de seu uso.

\section{Considerações finais}

A emergência das mídias móveis vem acelerando a execução de tarefas diárias pela sociedade. Observa-se que esses novos artefatos modificam as experiências do sujeito e refletem diretamente nas dinâmicas dos espaços urbanos. Com isso, a presente pesquisa buscou investigar diversas classes de aplicativos móveis como estratégia complementar de projeto. Para isso, utilizou-se de uma oficina pedagógica com estudantes de Arquitetura e Urbanismo, para a realização de análises e leituras de objetos midiáticos por meio da aplicação do método close reading.

Pode-se dizer que o close reading se apresentou como um instrumento capaz de proporcionar compreensões acerca das funcionalidades de uma mídia móvel como extensora de atividades do mundo físico. $O$ uso do método em conjunto das poéticas das novas mídias proporcionou compreensões sobre o design do artefato, a experiência subjetiva do usuário e as relações espaciais. O método se revelou como uma ferramenta pedagógica capaz de complementar as investigações da realidade, proporcionando o entendimento de relações virtuais que refletem nos espaços físicos.

Frente ao experimento pedagógico direcionado para o projeto arquitetônico e urbano, foi possível investigar como estudantes consideram e avaliam as possibilidades de se pensar, criticamente, o espaço mediado por mídias móveis. Foi observado que diversos aplicativos, que não foram criados para fins arquitetônicos e urbanísticos, influenciam diretamente nas diversas ações do sujeito como parte integrante da cidade. Além disso, as percepções de leitura de aplicativos podem se tornar informações complementares no diagnóstico arquitetônico, o que levará a novas propostas de solução de projeto.

Destaca-se que, de acordo com a natureza de cada aplicativo, observa-se determinadas condutas urbanas, que alteram as dinâmicas de uso e ocupação dos espaços. Assim, a partir da aplicação do close reading, faz-se possível investigar esses padrões, direcionando para reflexões de seu uso como instrumento de projeto. Um exemplo desta situação são os aplicativos que coordenam os sistemas de transporte público, em que, a partir da sincronização das informações com objetos físicos, nota-se o direcionamento de padrões comportamentais nos pontos de ônibus baseados na informação.

Além disso, também foi verificado que, a partir da produção, análise e monitoramento das informações geradas pelos próprios usuários, faz-se possível estabelecer critérios de intervenção, arquitetônica e urbana, fundamentadas pela camada informacional. 
Isso é, a leitura de aplicativos se torna um instrumento que, se utilizado juntamente com outras estratégias de projeto, pode potencializar as interações, usos e apropriações dos espaços, principalmente os espaços abertos.

À vista disso, foi observado que as possíveis intervenções, decorrentes das informações obtidas pelas leituras de objetos de mídia, podem se materializar em diversas formas, constituindo-se, desde pequenas intervenções físicas em mobiliários urbanos e fachadas de edifícios, até intervenções espaciais de infraestrutura urbana. As leituras também oferecem subsídio para a esfera política e legal da cidade, as quais podem ser utilizadas como instrumento de planejamento e gestão urbana.

Em função das potencialidades observadas pelo trabalho, ressalta-se a necessidade de incorporar conteúdo acerca de mídias digitais nos cursos de Arquitetura e Urbanismo, visto que esse novo paradigma cultural influencia as realidades locais e, consequentemente, no escopo para desenvolvimento de projetos de Arquitetura e Urbanismo. Portanto, a utilização das mídias móveis associadas ao processo de projeto pode ser vista como uma oportunidade de integrar cidades e sistemas digitais, proporcionando novas formas de se esboçar arquitetura e urbanismo na era digital.

Por fim, destaca-se que esse artigo contribui para a academia a partir da utilização do método close reading com lentes analíticas voltadas para a compreensão das dinâmicas culturais no espaço. Porém, para a conformação do tópico em estudo, faz-se necessário pesquisas futuras na área, com um maior campo de abrangência.

\section{Agradecimentos}

O presente trabalho foi realizado com apoio da Coordenação de Aperfeiçoamento de Pessoal de Nível Superior Brasil (CAPES) - Código de Financiamento 001 - e do Grupo de Modelagem Avançada da Universidade Federal de Santa Catarina (GMA-UFSC).

\section{Notas}

(1) Projetos e exibições de Lev Manovich: http://manovich.net/index.php/exhibitions. Último acesso em 18 de agosto de 2020.

(2) Por se tratar de uma pesquisa experimental na área da educação, envolvendo alunos da graduação, a pesquisa foi aprovada para execução em 09 de abril de 2019, pelo Comitê de Ética em Pesquisa com Seres Humanos (CEPSH-UFSC), sob parecer de $n^{\circ} 3.252 .937$.

\section{Referências}

ANDRADE, Max L. V. X. De; RUSCHEL, Regina Coeli; MOREIRA, Daniel de Carvalho. O processo e os métodos. In: KOWALTOWSKI, Doris C. C. K.; MOREIRA, Daniel de Carvalho; FABRÍCIO, Márcio M. (Eds.). O processo de projeto em arquitetura: da teoria à tecnologia. São Paulo: Oficina de Textos, 2011. p. 80-110.

BARDIN, Laurence. Análise de Conteúdo. Lisboa: Edições 70, 2004.

BIZZOCCHI, Jim. Ceremony of Innocence and the Subversion of Interface: Cursor Transformation as a Narrative Device. In: INTERNATIONAL DIGITAL ARTS AND CULTURE CONFERENCE, 5., 2003, Melbourne. Proceedings [...]. Melbourne: Streaming Wor(I)ds, 2003.

BIZZOCCHI, Jim. Games and narrative: An analytical framework. Loading - the Journal of the Canadian Games Studies Association, v. 1, n. 1, p. 5-10, 2007.

BIZZOCCHI, Jim; LIN, M. A. Ben; TANENBAUM, Joshua. Games, narrative and the design of interface. International Journal of Arts and Technology, v. 4, n. 4, p. 460-479, 2011. DOI: 10.1504/IJART.2011.043445 
FARIA, Gustavo Henrique Campos de et al..

Leitura de mídias móveis como estratégia complementar de projeto

BIZZOCCHI, Jim; TANENBAUM, Joshua. Well read: applying close reading techniques to gameplay experiences. In: DAVIDSON, Drew (Ed.). Well Played 3.0: Video Games, Value, and Meaning. Pittsburgh: ETC Press, 2011. p. $262-290$.

BOLTER, J. David; GRUSIN, Richard. Immediacy, Hypermediacy, and Remediation. In: BOLTER, J. David; GRUSIN, Richard. Remediation. Cambridge: MIT Press, 1999. p. 20-50.

DE SOUZA E SILVA, Adriana. From cyber to hybrid: Mobile technologies as interfaces of hybrid spaces. Space and Culture, v. 9, n. 3, p. 261-278, 2006. DOI: https://doi.org/10.1177/1206331206289022

EICHNER, Susanne. Agency and Media Reception: Experiencing Video Games, Film, and Television. Potsdam, Germany: Springer VS, 2013.

FARIA, Gustavo Henrique Campos De; VAZ, Carlos Eduardo Verzola; FADEL, Luciane Maria. Parâmetros de design na análise e leitura de artefatos midiáticos. In: SIMPÓSIO BRASILEIRO DE TECNOLOGIA DA INFORMAÇÃO E COMUNICAÇÃO NA CONSTRUÇÃO. 2., 2019, Campinas. Anais [...]. Campinas: ANTAC, 2019.

FROSH, Paul. The Poetics of Digital Media. $1^{\text {a }}$ ed. Medford, MA: Polity Press, 2019.

GASTAL, Susana. Imaginário Urbano: relendo o texto praça. In: CONGRESSO DA ASSOCIAÇÃO PORTUGUESA DE CIÊNCIAS DA COMUNICAÇÃO, 3., 2004, Covilhã. Actas do III SOPCOM, VI LUSOCOM E II IBÉRICO. Portugal: SOPCOM. Disponível em: http://www.labcom-ifp.ubi.pt/ficheiros/20110829-actas_vol_2.pdf.

GUNNING, Tom. The Cinema of Attraction. In: ELSAESSER, Thomas (Ed.). Early cinema: Space, frame, narrative. Londres: BFI Publishing, 1990. v. 3p. 63-70.

HOELZL, Ingrid; MARIE, Rémi. Brave New City: the image in the urban data-space. Visual Communication, v. 15, n. 3, p. 371-391, 2016. DOI: https://doi.org/10.1177/1470357216642638

JIN, Jiayi. New Poetics of Augmented Space: Re-conceptualise Augmented Space Based on Fundamentals of Augmented Reality. In: Lecture at the Conference of Museums and the Web (MW2016). Los Angeles, 2016.

JONES, John Chris. A Method of Systematic Design. In: CONFERENCE ON DESIGN METHODS. 1963, Oxford. Anais [...]. Oxford: Pergamon Press, 1963.

LAWSON, Bryan. How Designers Think : The design process demystified. 4 ed. ed. Oxford: Architectural Press, 2005 .

LEMOS, André. Mídias Locativas e Territórios Informacionais. In: SANTAELLA, Lúcia; ARANTES, Priscila (Eds.).

Estéticas Tecnológicas: Novos Modos de Sentir. São Paulo: EDUC, 2007. p. 207-230.

LEMOS, André. Cibercultura y movilidad: una era de conexión. Razon y Palabra, v. 22, n. 1_100, p. 107-133, 2018. Disponível em: https://www.revistarazonypalabra.org/index.php/ryp/article/view/1145. Acesso em: 20 ago. 2019.

MANOVICH, Lev. The Language of New Media. Cambridge: MIT Press, 2001.

MANOVICH, Lev. Novas mídias como tecnologia e idéia: dez definições. In: LUCIA LEÃO (Ed.). 0 chip e o caleidoscópio: reflexões sobre as novas mídias. São Paulo: SENAC, 2005. p. 24-50.

MANOVICH, Lev. The poetics of augmented space. Visual Communication, v. 5, n. 2, p. 219-240, 2006. DOI: https://doi.org/10.1177/1470357206065527

MCQUIRE, Scott. The Media City: Media, Architecture and Urban Space. Londres: Sage Publications, 2010.

MISKOLCI, Richard. Desejos Digitais: Uma análise sociológico da busca por parceiros online. Belo Horizonte: Ed. Autêntica, 2017.

MITCHELL, William J. E-topia: A vida urbana - mas não como a conhecemos. São Paulo: Senac, 2002. 
FARIA, Gustavo Henrique Campos de et al..

Leitura de mídias móveis como estratégia complementar de projeto

MURRAY, Janet. Agency. In: The Aesthetics of the Medium. Cambridge: MIT Press, 1998. p. 126-153.

NORBERG-SCHULZ, Christian. O fenômeno do lugar. In: NESBITT, Kate (Ed.). Uma nova agenda para a arquitetura: antologia teórica (1965-1995). $2^{\mathrm{a}}$ ed. São Paulo: Cosac Naify, 2008. p. 443-461.

PLATÃO, Francisco; FIORIN, José Luiz. Para entender o texto: leitura e redação. São Paulo: Editora Ática, 1999.

PLATÃO, Francisco; FIORIN, José Luiz. Lições de texto: leitura e redação. São Paulo: Editora Ática, 2006.

RIBEIRO, José Carlos Santos; LIMA, Leonardo Branco. Mapas colaborativos digitais e (novas) representações sociais do território: uma relação possível. CiberLegenda, n. 25, p. 38-47, 2012. Disponível em:

https://periodicos.uff.br/ciberlegenda/article/view/36882. Acesso em: 21 ago. 2020.

RICUPERO, Paulo. Ciclistas esbanjam criatividade em desenhos feitos com GPS. 2017. Disponível em: https://www.ativo.com/bike/papo-de-pedal/desenhos-feitos-com-gps/ . Acesso em: 9 ago. 2019.

ROWE, Peter G. Design Thinking. Revided ed ed. Cambridge e Londres: MIT Press, 1991.

RYAN, Marie-Laure. Avatars of Story. University of Minnesota Press, p. 6-16, 2006.

SALEN, Katie; ZIMMERMAN, Eric. Rules of Play: Game design fundamentals. London: MIT Press, 2003.

THEOHARIDOU, Marianthi; MYLONAS, Alexios; GRITZALIS, Dimitris. A risk assessment method for smartphones. In: GRITZALIS, D. FURNELL, S.; THEOHARIDOU, M. (eds) Information Security and Privacy Research. SEC 2012. IFIP

Advances in Information and Communication Technology, vol 376. Springer, Berlin, Heidelberg. DOI:

https://doi.org/10.1007/978-3-642-30436-1_36

TOSCANO, Patrizia. Instagram-City: New Media, and the Social Perception of Public Spaces. Visual Anthropology, v. 30, n. 3, p. 275-286, 2017. DOI: https://doi.org/10.1080/08949468.2017.1296313

VALADARES, Alberto Guerra; TEODORO, Pacelli Henrique Martins. Territórios ampliados: entre o ciber e o espaço. Pós. Revista do Programa de Pós-Graduação em Arquitetura e Urbanismo da FAUUSP, v. 26, n. 49, p. e154021, 2019. DOI: https://doi.org/10.11606/issn.2317-2762.posfau.2019.154021

WIETHOFF, Alexander; HUSSMANN, Heinrich. Media Architecture: Using Information and Media as Construction Material. Berlin: De Gruyter, 2017.

\section{${ }^{1}$ Gustavo Henrique Campos de Faria}

Arquiteto e Urbanista. Mestre. Estudante à nível de doutorado pelo Programa de Pós-Graduação em Arquitetura e Urbanismo (NPGAU) da Escola de Arquitetura da Universidade Federal de Minas Gerais (EA-UFMG). Endereço postal: Rua Paraíba, 697, sala 300, Savassi, Belo Horizonte, MG, 30130-141.

\section{${ }_{2}^{2}$ Carlos Eduardo Verzola Vaz}

Arquiteto e Urbanista. Doutor. Docente no Departamento de Arquitetura e Urbanismo da Universidade Federal de Santa Catarina. Endereço postal: Rua Engenheiro Agronômico Andrei Cristian Ferreira, s/n, Trindade, Florianópolis, SC, 88040-970.

\section{Sara Dotta Correa \\ Arquiteta e Urbanista. Estudante à nível de mestrado pelo Programa de Pós-Graduação em Arquitetura e Urbanismo (PósARQ) da Universidade Federal de Santa Catarina (UFSC). Endereço postal: Rua Engenheiro Agronômico Andrei Cristian Ferreira, s/n, Trindade, Florianópolis, SC, 88040-970.}

4 Larissa Pereira de Souza

Arquiteta e Urbanista. Mestre. Endereço postal: Rua Engenheiro Agronômico Andrei Cristian Ferreira, s/n, Trindade, Florianópolis, SC, 88040-970. 